\title{
Comparison of clinical efficacy and safety between salbutamol-ipratropium bromide nebulization and salbutamol alone in children with asthmatic attack
}

\author{
Lusiana Kartininingsih, Landia Setiawati, Makmuri MS
}

\begin{abstract}
Background Indonesian guidelines for childhood asthma recommend giving ipratropium bromide when there are no improvement after 2 times salbutamol nebulization. The efficacy and safety of early nebulization of ipratropium bromide combined with salbutamol as first line in moderate asthma exacerbation in children are still unknown.

Objective To compare efficacy and safety between nebulized salbutamol-ipratropium bromide and salbutamol alone in children with moderate asthma exacerbation.

Methods Fifty-two children (2-6 years) with acute asthma (clinical score 5-10) were enrolled into a randomized single blind controlled trial comparing 2 groups of 2.5 mg nebulized salbutamol (group 1) and $2.5 \mathrm{mg}$ salbutamol combined with $0.5 \mathrm{mg}$ ipratropium bromide (group 2). Nebulization was given until clinical score decreased $<5$, maximum of 3 doses during 2 hours. Clinical measurements included clinical score, oxygen saturation and side effects which were assessed every 20 minutes up to 120 minutes. Statistical test for homogeneity and comparison of clinical outcomes and side effects used independent t-test, Fisher's exact test, and MannWhitney $U$ test $(\mathrm{P}<0.05)$.

Results The groups were similar in all baseline measures. There were significantly decreasing clinical score in groups 2 at 20, 40, $60,80,100$, and 120 minutes $(P<0.05)$, and the means of oxygen saturation were significantly higher in group 2 at 20,40,60, 80 , 100 , and 120 minutes $(P<0.05)$. In group $1,11.5 \%$ of patients were hospitalized after the study and none in groups $2(P>0.05)$. There were no toxic effects attributable to ipratropium bromide, and the side effects were not different between these two groups.

Conclusion The combination of nebulized ipratropium bromide and salbutamol in a child with acute moderate asthma exacerbation was associated with higher reduction of clinical score and higher oxygen saturation, and may reduce hospitalization [Paediatr Indones 2006;46:241-245].
\end{abstract}

Keywords: childhood asthma, ipratropium bromide, salbutamol, nebulization

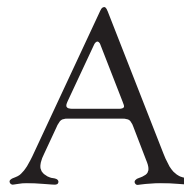

sthma prevalence, hospitalization rate, and deaths have increased according to epidemiologic studies from the 1970s and 1980s. ${ }^{1}$ These result in an increased attention on asthma management, including in children. An expert committee convened by the National Heart, Lung, and Blood Institute of the National Institutes of Health, published a guideline for asthma management in children. The national consensus of childhood asthma by UKK Pulmonology of Indonesian Pediatric Society also gives a guideline that the initial treatment of children with acute asthmatic attack is nebulized salbutamol until 2 times in 20 minutes duration. If there is no improvement in clinical outcomes, anticholinergic drugs is then added. 2,3

Inhaled anticholinergic agents such as atropine have long been known to be effective for acute asthma, but until recently their use has been limited because of the systemic side effects. Ipratropium bromide is a synthetic derivate of atropine that was designed to act lo-

From the Department of Child Health, Medical School, Airlangga University, Surabaya, Indonesia.

Reprint request to: Lusiana Kartininingsih, MD, Department of Child Health, Medical School, Airlangga University, Jl. Prof. Moestopo 6-8, Surabaya, Indonesia. Tel /Fax. 62-31-5501748. 
cally in the lung with minimal systemic absorption. ${ }^{4}$ Studies of efficacy and safety of ipratropium has been conducted predominantly in adults. If it is used alone, ipratropium bromide has been shown to reduce bronchospasm with minimal cardiovascular or other systemic effects. When combined with $\beta$-agonist, ipratropium bromide improves pulmonary function above that seen with $\beta$-agonist alone. ${ }^{5}$

The role of ipratropium in pediatric asthma therapy is limited. Several studies of children with severe asthma exacerbation have found improvement in pulmonary function when ipratropium bromide was added to $\beta$-agonist. ${ }^{6-8}$ But the benefit of ipratropium bromide with $\beta$-agonist combination in children with moderate asthma exacerbation and among young children who were unable to perform pulmonary test was still unknown. The purpose of this study was to compare clinical outcomes and side effects of nebulized $2.5 \mathrm{mg}$ salbutamol combined with $0.5 \mathrm{mg}$ ipratropium bromide and $2.5 \mathrm{mg}$ salbutamol alone in children with moderate asthma exacerbation.

\section{Methods}

Patients aged 2-6 years presenting to the emergency department with wheezing were eligible for enrollment if clinical score between 5-10, and the parents agreed to enroll in this study. Patients were excluded if they showed signs of respiratory failure, pneumonia and congenital heart abnormality, or already got oral bronchodilator 6 hours before. The initial clinical score and oxygen saturation were assessed at first examination. Our clinical-scoring system, a modification of one published by Bentur, rated the severity of an episode according to signs and symptoms (Table 1).
The study was designed as a single-blind, randomized, controlled trial to compare nebulized salbutamol alone as a standard asthma treatment protocol in the pediatric emergency department of Soetomo Hospital, Surabaya, with combination of salbutamol and ipratropium bromide. The study took place between October 2004 and February 2005. Data were collected from their parents; clinical scores, oxygen saturations, and chest $\mathrm{x}$-rays were assessed before the first nebulizer treatment. The total of clinical score was divided into three categories: 0-4 mild exacerbations, 5-10 moderate exacerbations, and $>10$ severe exacerbations. Only patients with clinical scores 5-10 (moderate exacerbation) were enrolled in our study. Patients were randomized into two groups, group 1 as the control group was treated with nebulized $2.5 \mathrm{mg}$ salbutamol; and group 2 as the treatment group was treated with nebulized $2.5 \mathrm{mg}$ salbutamol and $0.5 \mathrm{mg}$ ipratropium bromide. Medications were administered with the use of a Bremed 5003 nebulizer and face-mask. Oxygen was administered when the patient's oxygen saturation (as measured by pulse oximetry) was $92 \%$ or less. Nebulizer was repeated for maximally 3 times until the clinical score was less than 5 . The principal outcome measure was the difference (between two groups) in the means of clinical score and decreasing clinical score during 2 hours observation. Secondary outcomes included the changes in oxygen saturation, hospitalization rates, number of nebulization and side effects between two groups. All outcome measures were taken at baseline (time 0 ), at 20, 40, 60, 80, 100, and 120 minutes. Children with no improvement in clinical score (score $>5$ ) at the end of the study were admitted. The discharged patients were sent to

Table 1. Clinical score by Bentur modification

\begin{tabular}{|c|c|c|c|c|}
\hline Score & Heart rate & $\begin{array}{l}\text { Respiratory } \\
\text { rate }\end{array}$ & Wheezing & $\begin{array}{l}\text { Acessories } \\
\text { muscle usage }\end{array}$ \\
\hline 0 & $<110$ & $<40$ & None & None \\
\hline 1 & $111-130$ & $40-50$ & End expiratory only & Mild \\
\hline 2 & $131-150$ & $51-60$ & $\begin{array}{l}\text { Inspiratory and expiratory } \\
\text { (with stethoscope) }\end{array}$ & $\begin{array}{l}\text { Moderate } \\
\text { (with tracheosternal) }\end{array}$ \\
\hline 3 & $>150$ & $>60$ & $\begin{array}{l}\text { Loud wheezing } \\
\text { without stethoscope } \\
\text { or silent chest }\end{array}$ & $\begin{array}{l}\text { Severe } \\
\text { with nasal flaring }\end{array}$ \\
\hline $\begin{array}{l}\text { Score } \\
\text { Total } \\
\text { score }\end{array}$ & & & & \\
\hline
\end{tabular}


Lusiana Kartininingsih et al: Salbutamol-ipratropium bromide nebulization vs salbutamol in asthmatic attack

TABle 2. Baseline characteristics of THE Study GROUP

\begin{tabular}{lcc}
\hline Variable & $\begin{array}{c}\text { Group 1 } \\
\mathbf{n = 2 6}\end{array}$ & $\begin{array}{c}\text { Group 2 } \\
\mathbf{n = 2 6}\end{array}$ \\
\hline $\begin{array}{l}\text { Sex } \\
\quad \text { Male }\end{array}$ & $12(46 \%)$ & $19(73 \%)$ \\
$\quad$ Female & $14(54 \%)$ & $7(2 \%)$ \\
Age (years) & $3.69(\mathrm{SD} \mathrm{1.49)}$ & $4.05(\mathrm{SD} 1.54)$ \\
Body weight (kgs) & $13.80(\mathrm{SD} 4.31)$ & $14.35(\mathrm{SD} 3.78)$ \\
Nutritional state & $17(65 \%)$ & $18(69 \%)$ \\
$\quad$ Good nutrition & $6(23 \%)$ & $7(27 \%)$ \\
$\quad$ Malnutrition & $3(12 \%)$ & $0(0 \%)$ \\
$\quad$ Severe malnutrition & $0(0 \%)$ & $1(4 \%)$ \\
$\quad$ Obese & $3(12 \%)$ & $4(15 \%)$ \\
Atopic history & $13(50 \%)$ & $17(65 \%)$ \\
$\quad$ All of parents & $6(23 \%)$ & $3(12 \%)$ \\
Only one of parents & $3(12 \%)$ & $2(8 \%)$ \\
$\quad$ Siblings & $1(4 \%)$ & $0(0 \%)$ \\
$\quad$ Other families & $3(12 \%)$ & $8(31 \%)$ \\
$\quad$ None or unknown & $23(89 \%)$ & $18(69 \%)$ \\
Immunotherapy & & \\
$\quad$ Yes & & \\
$\quad$ No & $6.98(\mathrm{SD} \pm 4.74)$ & $9.85(\mathrm{SD} 9.16)$ \\
Duration of exacerbation \\
(hours)
\end{tabular}

* No significant difference with $\mathrm{P}>0.05$

outpatient clinic in the next day to evaluate the clinical condition and side effect after 24 hours. Ethical team of Department of Child Health has agreed to the design of this study.

The baseline characteristics were analyzed by chisquare test, Fisher's exact test, and Mann-Whitney U test. The primary outcomes and secondary outcomes were analyzed with independent $\mathrm{t}$-test, chi-square test, Fisher's exact test, and Mann-Whitney U test.

\section{Results}

A total of 52 children were collected during October 2004 until February 2005. Twenty-six children are in each group. Table 2 showed the baseline characteristics of the study groups. Age, sex, body weight, nutritional state, atopic history, immunotherapy, duration of exacerbation, initial clinical score, and oxygen saturation were not differ between two groups.

Figure 1 shows the means of clinical scores between the two groups at baseline, 20,40,60, 80, 100, and 120 minutes. There was no significant difference in the means of clinical score at baseline, minutes 40 , minutes 60 , minutes 80 and minutes 120 . At minutes 20 , the mean of clinical score in group 1 was 4.81 compared with 3.81 in group $2(\mathrm{P}<0.05)$. At minutes 100 , the mean of clinical score in group 1 was 2.85 compared with 1.92 in group $2(\mathrm{P}<0.05)$. But the decreasing of clinical score between two group at minutes $20,40,60,80,100$, and 120 were significantly higher in group $2(\mathrm{P}<0.05)$ at minutes $20,40,60,80$, 100 , and 120.

Figure 2 shows improvement of oxygen saturation from baseline to minutes $20,40,60,80,100$, and 120. At the baseline the mean of oxygen saturation was $93.15 \%$ in group 1 and 94.15 in group 2, which showed no significant difference $(\mathrm{P}>0.05)$. The means of oxygen saturation improved more significantly in group 2 compare with group 1 at minutes 20, 40, 60, 80,100 , and 120 .

After treatment for maximally 3 times during 2 hours observation, 3 patients in group 1 showed

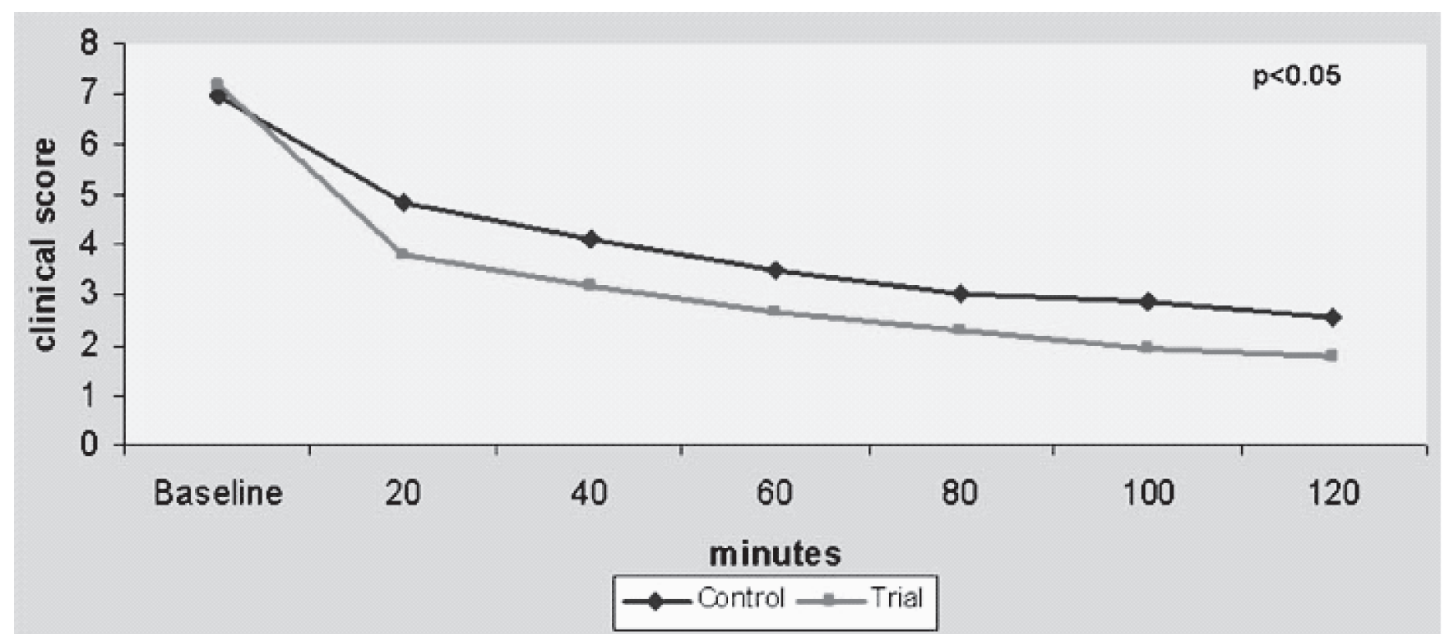

Figure 1. The meANS of CLINICAL SCORE AT BASELINE AND DURING OBSERVATION 


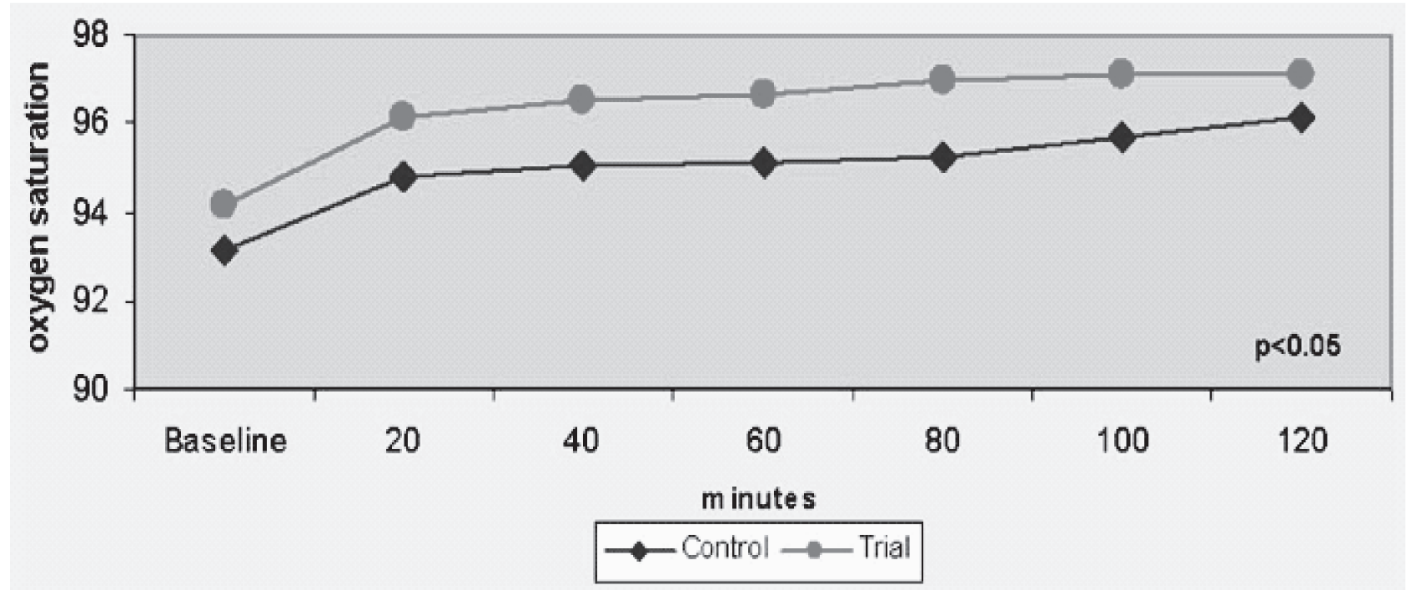

Figure 2. THE MEANS OF OXYGEN SATURATION AT BASELINE AND DURING OBSERVATION

Table 3. Outcomes after maximally 3 time's nebulization

\begin{tabular}{llccc}
\hline No & Outcomes & $\begin{array}{c}\text { Group 1 } \\
\mathbf{n}=\mathbf{2 6}\end{array}$ & $\begin{array}{c}\text { Group 2 } \\
\mathbf{n = 2 6}\end{array}$ & P value \\
\hline 1 & Improved (discharged) & $23(88.5 \%)$ & $26(100 \%)$ & 0.235 \\
2 & Failure (hospitalized) & $3(11.5 \%)$ & $0(0 \%)$ & \\
\hline
\end{tabular}

no improvement in clinical score, compared with no patient failure in group 2, but this result was not significant $(\mathrm{P}>0.05)$.

During the 2 hours of observation, side effects between two groups were noted, and showed at Figure 3. There were no differences in increased heart

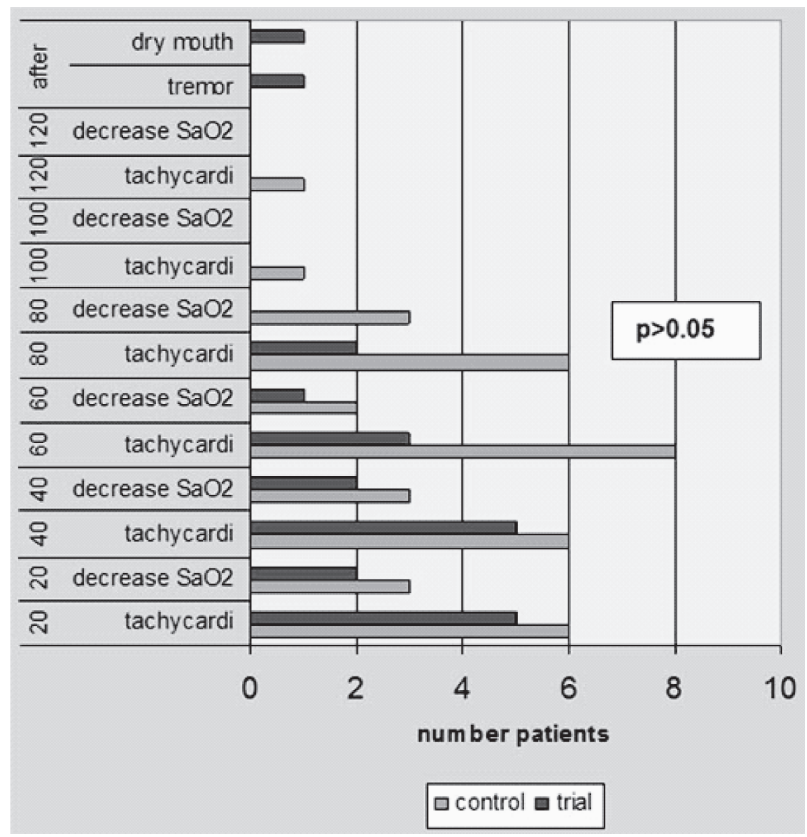

TABle 3. Outcomes After maximally 3 time's nebulization rate, decreased oxygen saturation, tremors and dry mouth, between 2 groups in 2 hours of observation. One patient in group 1 showed side effect of vomiting during observation, and in group 2, there were 2 patients with vomiting and 1 patient with more frequent cough, but not statistically significant among two groups.

\section{Discussion}

We found that giving ipratropium bromide combined with salbutamol for acute moderate exacerbation of asthma in children could significantly increased clinical score after treatment and improvement in oxygen saturation. We also found no significant difference in hospitalized patients. On the basis of our data, approximately nine children with moderate exacerbation of asthma would need to be treated with combination of salbutamol and ipratropium bromide to prevent one incidence of hospitalization.

Ipratropium bromide is an effective bronchodilator for patients with acute asthma. Studies of the effectiveness of a combination of ipratropium bromide and a $\beta 2$-adrenergic agonist in adults with an acute exacerbation of asthma have produced conflicting results. ${ }^{5}$ In contrast, but not all, studies in children have shown that the addition of ipratropium bromide to a nebulized $\beta 2$-adrenergic agonist has additive effects in improving pulmonary function. ${ }^{6-8}$

In a study of 125 children with severe asthma, Schuh and coworkers found that the forced expiratory volume in one second improved to a greater extent in 
children receiving salbutamol and ipratropium than in those receiving albuterol and placebo, but there was no effect on overall rates of hospitalization. In a subgroup analysis of children in whom the forced expiratory volume in one second was less than 30 percent of the predictive value, the hospitalization rate among those receiving the combination therapy was significantly lower than the rate with salbutamol alone; however, the small number of patient limited the extent to which these observations could be generalized. ${ }^{6}$ Qureshi and coworkers ${ }^{7}$ in a study of 434 children with moderate and severe asthma exacerbation showed that the addition of ipratropium bromide had a significant effect on improvement of the asthma score, but there were no significant difference in improvement of the peak expiratory flow rate.Sharma and coworkers ${ }^{9}$ in 2004 showed that frequent combined nebulization with salbutamol and ipratropium bromide significantly improved percentage of PEFR starting at 30 minutes and lasting for 4 hours in 50 children (6-14 years) with moderate asthma exacerbation in India.

Comparison of the treatment and control groups in our study showed that the clinical score improved to a greater extent in children receiving combination of salbutamol and ipratropium bromide than in those receiving salbutamol alone which starting in 20 minute and lasting for 2 hours. We did not examine pulmonary function test, because our subjects aged were $2-6$ years, in which the pulmonary function test was difficult to measure. We also found that oxygen saturation was significantly increased in combination group, but actually there were no means because all of our subjects were not in hypoxic condition Although our study showed that in control group $11.5 \%$ of patient needed hospitalization because there were no improvements after 3 times of nebulization, there was no statistically difference in hospitalization rate.

Ipratropium bromide is of low lipid solubility, and thus is poorly absorbed systemically. Toxic effects of this drug are therefore negligible, even at very high doses, because only less than $1 \%$ which found in blood. ${ }^{4}$ Our study did not show any differences in side effects between the groups.

This study had some limitations. Pulmonary function test were not performed in these patients.
GINA (Global Initiative for Asthma) noted that pulmonary function test (spirometry or peak flow meter) was integral parts to assess the severity of asthma exacerbation, and clinical evaluation. The sample size was too small to evaluate hospitalization rates among the groups.

We concluded that our study demonstrated the benefit and safety of the combination of nebulized ipratropium bromide and salbutamol as first line treatment in children with acute moderate asthma exacerbation with higher reduction of clinical score and higher oxygen saturation, and thus might reduce hospitalization.

\section{References}

1. Liu A, Spahn J, Leung D. Childhood Asthma. In: Behrman RE, Kliegman RM, Nelson WE, editors. Textbook of Pediatrics, 17th edition. Philadelphia: Elsevier, 2004:760-74.

2. NHLBI/WHO. Global initiative for asthma, NHLBI/ WHO workshop report, 1995.

3. Rahajoe N, Supriyanto B, Budi Setyanto D. Tatalaksana serangan asma. In: Rahajoe N, Supriyanto B, Budi Setyanto D, editors. Pedoman nasional asma anak. UKK Pulmonologi-PP IDAI, 2004: 25-34

4. Gross NJ. Ipratropium bromide. N Eng J Med, 1988:319(8),486-94.

5. Rodrigo GJ, Rodrigo C. The role of anticholinergics in acute asthma treatment. An evidence-based evaluation. Chest, 2002;121(6):1977-87.

6. Schuh S. Efficacy of frequent nebulized ipratropium bromide added to frequent high-dose albuterol therapy in severe childhood asthma. J Pediatr, 1995:126,639-45.

7. Qureshi F, Pestian J, Davis P, Zaritsky A. Effect of nebulized ipratropium on the hospitalization rates of children with asthma. N Engl J Med,1998:339,1030-5.

8. Plotnick LH, Ducharme FM. Should inhaled anticholinergics be added to $\beta 2$ agonists for treating acute childhood and adolescent asthma? A systematic review. BMJ,1998:317,971-7.

9. Sharma A and Madaan A (2004). Nebulized salbutamol vs salbutamol and ipratropium combination in asthma. Indian J Pediatr 71(2), 121-4. 